\title{
CD20/CD79a/PAX5/CD3-negative post-transplant lymphoma with aberrant actin and desmin co-expression-a potential differential diagnostic pitfall between PTLD and PTSMT
}

\author{
Jan-Theile Suhren $^{1} \cdot$ Jerome Schlué $^{1} \cdot$ Hans Kreipe ${ }^{1} \cdot$ Kais Hussein $^{1}$ \\ Received: 25 November 2020 / Accepted: 3 January 2021 / Published online: 18 February 2022 \\ (C) The Author(s) 2022
}

Dear Editor,

Post-transplant lymphoproliferative disorders (PTLD) are commonly $\mathrm{CD} 20^{+}$and rarely $\mathrm{CD} 20^{-}[1]$. Co-expression of mesenchymal/muscle markers is unusual in PTLD and nonPTLD lymphomas [2]. The main clinical differential diagnosis is the manifestation of a post-transplant smooth muscle tumour (PTSMT) [3, 4]. Both types of post-transplant tumours can manifest at any anatomic location and present with similar clinical features $[3,4]$.

In our case study, the male patient had previously been diagnosed with primary sclerosing cholangitis, autoimmune hepatitis and colitis ulcerosa. Seventy-four months after liver transplantation, at the age of 22 years, the patient complained about upper abdominal pain and fever. Subsequently, a left-sided liver tumour of $4.4 \mathrm{~cm}$ was found. Biopsy showed a large cell neoplasm, which was $\mathrm{CD} 20^{-} / \mathrm{CD} 79 \mathrm{a}^{-} / \mathrm{PAX}^{-} / \mathrm{CD}^{-}$but diffusely smooth muscle actin $^{+}$, focal desmin ${ }^{+}$, partial Epstein-Barr virus (EBV)-encoded small RNAs (EBER) ${ }^{+}$as well as $\mathrm{CD} 10^{+}, \mathrm{CD} 30^{(+)}$and MYC proto-oncogene (c-MYC) ${ }^{+}$ (Fig. 1). At first, an unusual high-grade PTSMT was suspected. However, further analyses revealed negativity

Kais Hussein

hussein@mvz-hhz.de

Institute of Pathology, Medizinische Hochschule Hannover, Carl-Neuberg-Strasse 1, 30625 Hannover, Germany for caldesmon but lambda light chain restriction and rearrangements of c-MYC and immunoglobulin heavy chain (IGH). Therefore, the diagnosis was plasmablastic PTLD and not PTSMT.

The patient refused treatment at the local hospital and died 5 months later.

Typically, sarcomatoid dedifferentiated lymphomas show spindle cells with high-grade atypia [5]. In contrast, PTSMT usually show spindle cells with low-grade atypia; however, high-grade PTSMT has been reported in some patients [4]. EBV-association and c-MYC expression can be found in both PTLD and PTSMT, while CD10 and CD30 are usually negative in PTSMT [3]. In most cases, EBV can be detected in all tumour cells, but, as in our case, partial EBER positivity could be the result of partial genetic loss of EBV in a sub-clone [6].

In general, PTLD and PTSMT can manifest in one patient but are considered unrelated tumour events [3, 4]. In the present case, we do not consider this lesion as a PTLD/PTSMT overlap neoplasm because analyses show PTLD-typical genetic defects, while PTSMT usually show no c-MYC/IGH rearrangements [3]. The differential diagnostic pitfall is the negativity of $\mathrm{B}$ and $\mathrm{T}$ cell markers, including PAX5, and the positivity for actin and desmin. Therefore, in this rare cases we recommend the evaluation of plasma cell and muscle markers, such as caldesmon, PCR and fluorescence in situ hybridisation, in order to differentiate between PTLD and PTSMT. However, we do not recommend routine testing of mesenchymal 


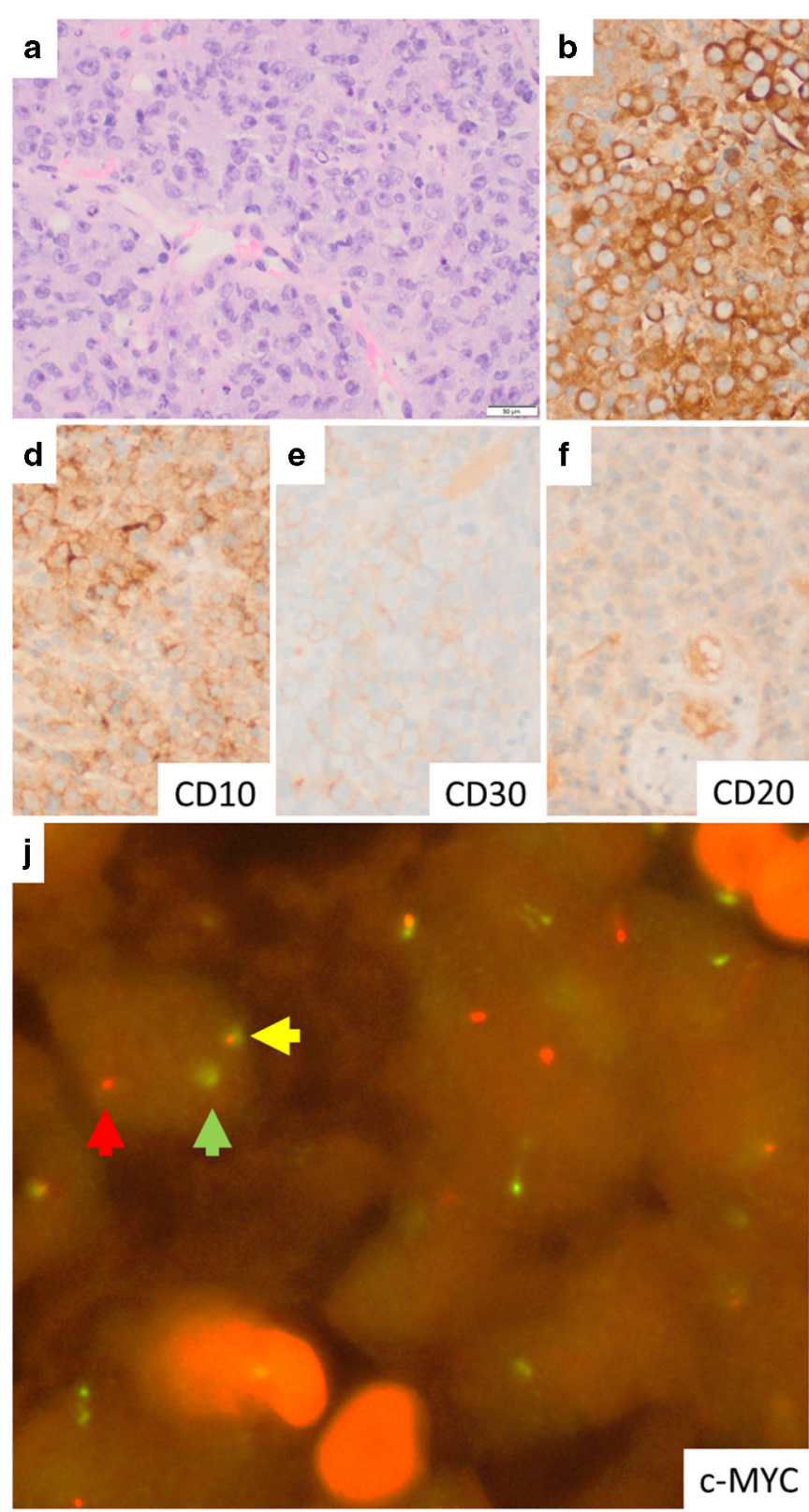

Fig. 1 (a) Histology of the biopsy showed large round to oval blastoid cells with large nuclei with prominent nucleoli (haematoxylin eosin stain). (b-i) Immunohistochemistry revealed lambda-positive plasmablastic tumour cells with aberrant mesenchymal marker expression (smooth muscle actin/SMA $>90 \%$ of tumour cells; $<5 \%$ desmin). Positivity was detected also for EBER ( 50\%), c-MYC (> 90\%), CD10 (>90\%), CD30 (30-40\%; weak), Ki67 (>90\%) and PDL1 $(\sim 60 \%)$; c-MYC, Ki67 and PDL1 are not depicted. The following

markers in PTLD because CD20 negativity is the most important adverse prognostic factor in PTLD and not anaplasia and/or aberrant marker expression itself [7].

While reduced immunosuppression can be applied in both tumour types, diagnostic discrimination remains relevant because different therapy strategies should be initiated. Rituximab therapy will be inefficient in patients with CD20PTLD, who may instead benefit from standard anti- c

SMA

desmin
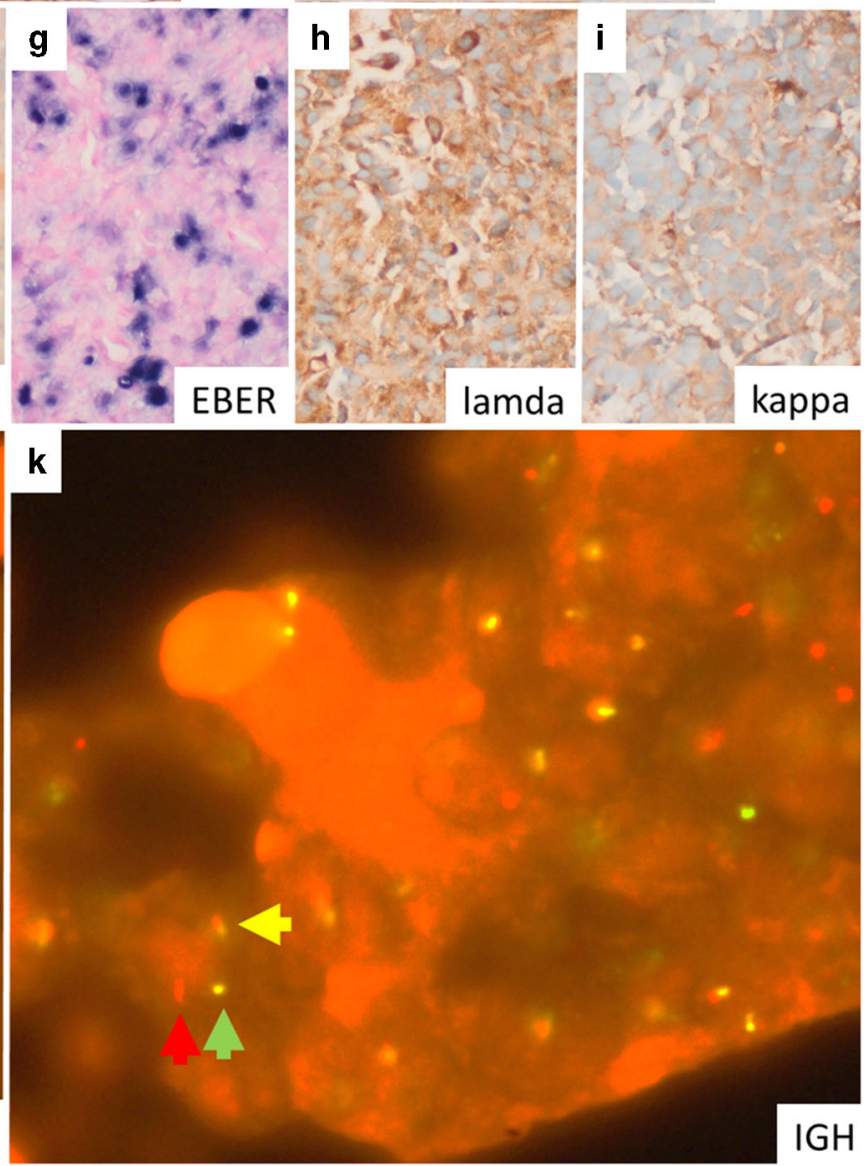

markers were negative: caldesmon, CD20, CD79a, PAX5, CD3, BCL2, granzyme B, perforin, CD52, CD34, CD117 and CK5/14. (j, k) Fluorescence in situ hybridisation showed split signals of c-MYC and IGH. BCL2 and BCL6 showed normal configuration (not depicted). Lambda light chain restriction was confirmed by RT-PCR; PCR showed a monoclonal IGH signal, and short tandem repeat PCR indicated recipient origin of the tumour cells (not depicted). Original magnification: $\mathbf{a}-\mathbf{i}$ each $\times 400 ; \mathbf{j}$ and $\mathbf{k}$ each $\times 1000$

lymphoma chemotherapy, despite the poorer prognosis in comparison with $\mathrm{CD} 20^{+}$PTLD patients [7]. If possible, surgery should be performed in patients with PTSMT because anti-sarcoma chemotherapy and/or radiation are often not effective [3].

In summary, this case shows that aberrant mesenchymal marker expression in CD20- PTLD could be a pitfall, potentially leading to misdiagnosis of a PTSMT. 
Acknowledgements The authors thank Karim Hussain, $\mathrm{PhD}$, for text editing.

Authors' contribution Histopathology, data collection, review of the literature, manuscript preparation, final approval (J-TS, JS, HK, KH), FISH (J-TS, KH).

Funding Open Access funding enabled and organized by Projekt DEAL.

\section{Compliance with ethical standards}

Conflict of interest The authors declare that they have no conflict of interest.

Ethical approval This article does not contain any studies with human participants or animals performed by any of the authors. The retrospective analysis of archived tissue samples has been approved by the local ethic committee (\#2893-2015).

Open Access This article is licensed under a Creative Commons Attribution 4.0 International License, which permits use, sharing, adaptation, distribution and reproduction in any medium or format, as long as you give appropriate credit to the original author(s) and the source, provide a link to the Creative Commons licence, and indicate if changes were made. The images or other third party material in this article are included in the article's Creative Commons licence, unless indicated otherwise in a credit line to the material. If material is not included in the article's Creative Commons licence and your intended use is not permitted by statutory regulation or exceeds the permitted use, you will need to obtain permission directly from the copyright holder. To view a copy of this licence, visit http://creativecommons.org/licenses/by/4.0/.

\section{References}

1. Kaleem T, Crozier JA, Menke DM, Sher T (2016) Post-transplant lymphoproliferative disorder presenting as CD20-negative plasmablastic lymphoma in the lung. Rare tumors 8(3):6220-6284. https://doi.org/10.4081/rt.2016.6220

2. Suzuki R, Seto M, Nakamura S, Nakagawa A, Hara K, Takeuchi K (2001) Sarcomatoid variant of anaplastic large cell lymphoma with cytoplasmic ALK and alpha-smooth muscle actin expression: a mimic of inflammatory myofibroblastic tumor. Am J Pathol 159(1):383384. https://doi.org/10.1016/s0002-9440(10)61706-3

3. Jonigk D, Laenger F, Maegel L, Izykowski N, Rische J, Tiede C, Klein C, Maecker-Kolhoff B, Kreipe H, Hussein K (2012) Molecular and clinicopathological analysis of Epstein-Barr virus-associated posttransplant smooth muscle tumors. Am J Transplant Off J Am Soc Transplant Am Soc Transplant Surg 12(7):1908-1917. https:// doi.org/10.1111/j.1600-6143.2012.04011.x

4. Hussein K, Maecker-Kolhoff B, Donnerstag F, Laenger F, Kreipe H, Jonigk D (2013) Epstein-Barr virus-associated smooth muscle tumours after transplantation, infection with human immunodeficiency virus and congenital immunodeficiency syndromes. Pathobiol: J Immunopathol Mol Cell Biol 80(6):297-301. https://doi.org/10. $1159 / 000351326$

5. Cerroni L, El-Shabrawi-Caelen L, Fink-Puches R et al (2000) Cutaneous spindle-cell B-cell lymphoma: a morphologic variant of cutaneous large B-cell lymphoma. Am J Dermatopathol 22(4):299 304. https://doi.org/10.1097/00000372-200008000-00001

6. Ikuta K, Ding M, Zhang F, Sixbey JW, Scott RS (2011) Epithelial cell retention of transcriptionally active, P3HR-1-derived heterogeneous Epstein-Barr virus DNA with concurrent loss of parental virus $\nabla$. J Virol 85(15):7634-7643. https://doi.org/10.1128/JVI.00045-11

7. Al-Mansour Z, Nelson BP, Evens AM (2013) Post-transplant lymphoproliferative disease (PTLD): risk factors, diagnosis, and current treatment strategies. Curr Hematol Malignancy Rep 8(3):173-183. https://doi.org/10.1007/s11899-013-0162-5

Publisher's note Springer Nature remains neutral with regard to jurisdictional claims in published maps and institutional affiliations. 